\title{
Tumor lamination in mediastinal giant tumors
}

\section{Laminação tumoral nos tumores gigantes do mediastino}

Elias Kallas, tCbC-MG'; Rafael Diniz Abrantes'; Alexandre Ciappina Hueb¹.

A B S TR A C T

Mediastinum tumors may grow slowly and reach giant proportions without symptoms, hindering surgical removal. Tumor big dimensions difficult surgical maneuvers, with risk of uncontrollable bleeding and prejudice to surrounding structures. It may be necessary the use of exceptional measures such as venous-venous circulatory deviation, pre-operatory embolization and total extracorporeal circulation. We describe the technique of tumor lamination that allows for complete or almost complete resection of such tumors that in many occasions are not resectable. The description is based on the results of four patients treated with mediastinum giant tumors.

Keywords: Thoracic Surgery. Mediastinal Neoplasms. Surgical Procedures, Operative.

\section{INTRODUCTION}

$\mathrm{M}$ ediastinal tumors may grow slowly and reach giant proportions without symptoms'. After that, they may cause compressive phenomena of major structures, with the appearance of symptoms, leading the patient to seek medical help. At this moment, surgical removal is difficult, due to the giant dimensions of tumor, that difficult surgical maneuvers due to the smallness of space and/or invasion of major neighbor structures. The main threat is uncontrollable bleeding and the involvement of major surrounding organs. In view of these difficulties, the surgeon uses exceptional maneuvers such as venous-venous circulatory deviation ${ }^{2}$. Video-assisted resection is indicated for smaller tumors and is unappropriated for big volume tumors $^{3}$. Also, it was proposed the use of pre-operatory embolization and total extracorporeal circulation ${ }^{4}$. In view of such aspects, we decided to present the tumor lamination technique, based on the results presented by four patients with giant mediastinal tumors submitted to this technique.

This work was initially submitted and approved by the Ethical Research committee of Fundação de Ensino Superior do Vale do Sapucaí by the number 1.873.568.

\section{TECHNIQUE}

Access route varied according to localization of tumor: for those located at the posterior mediastinum, it was used thoracotomy at the $6^{\text {th }}$ intercostal space, right or left (Figure 1); for those located at the antero-superior mediastinum it was accessed by median sternotomy (Figure 2). Once reached, the tumor is incised with thermal-cautery, and tumor tissue slices are removed, maintaining its capsule, avoiding lesion of adjacent structures (Figure 3). These maneuvers are repeated until the tumor is internally removed, maintaining a thin external lamina or capsule, when that is well defined (Figure 4). Then, the capsule is mobilized (after tumor internal removal) and the vascular pedicle is exposed and treated. Tumor capsule preservation or its external layers ease surgical maneuvers to reach surrounding structures and vascular pedicle. When it is not possible to identify the capsule, tumor lamination remove laminar fragments and therefore tumor volume, reducing its size, easing mobilization and pedicle approach (Figure 5). When major structures are involved, lamination must be interrupted in the vicinities as occurred in one of our patients, with invasion of brachial plexus and subclavian

1 - Hospital das Clínicas Samuel Libânio, Serviço de Cirurgia Cardiotorácica, Pouso Alegre, MG, Brasil. 
vessels (Figure 6). Region is delimited with metallic clips to orientate adjuvant therapy.

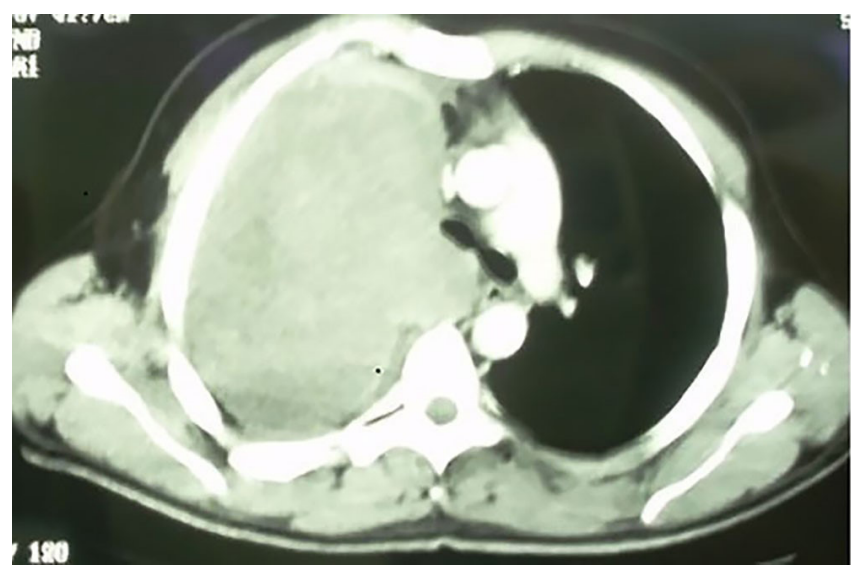

Figure 1. Giant tumor of posterior mediastinum

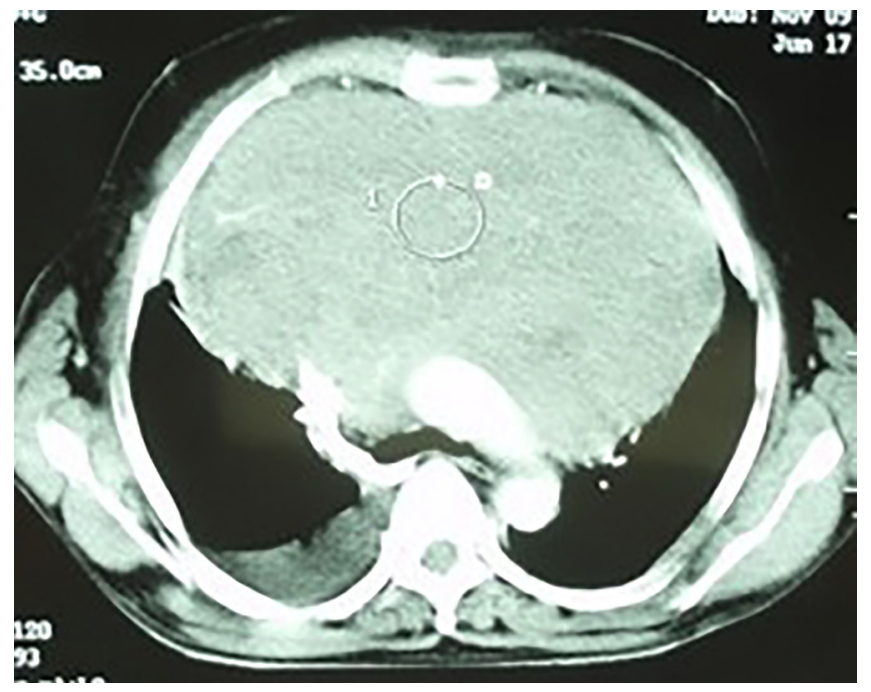

Figure 2. Giant tumor of antero-superior mediastinum.

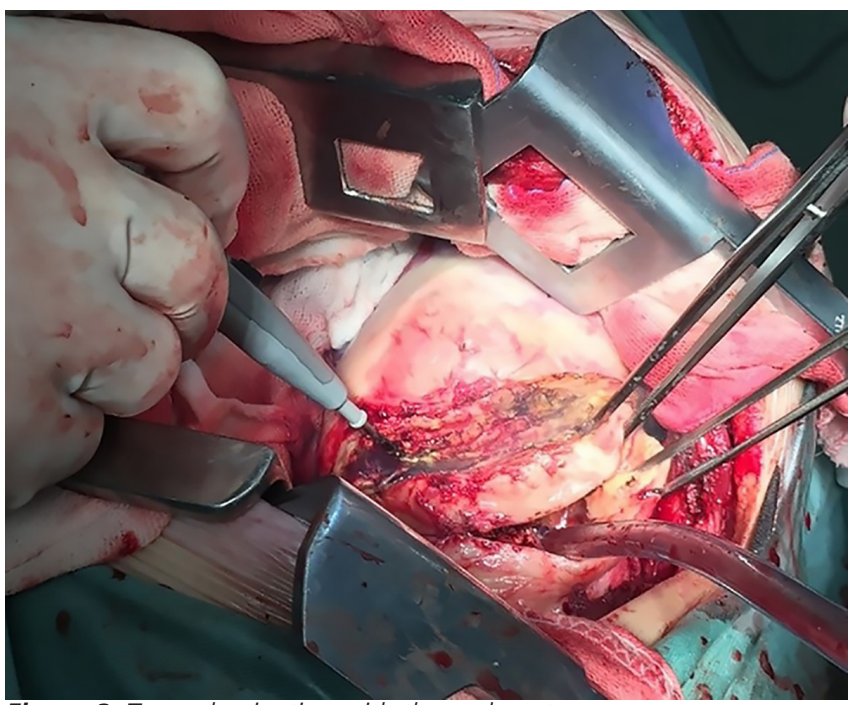

Figure 3. Tumor lamination with thermal-cautery.

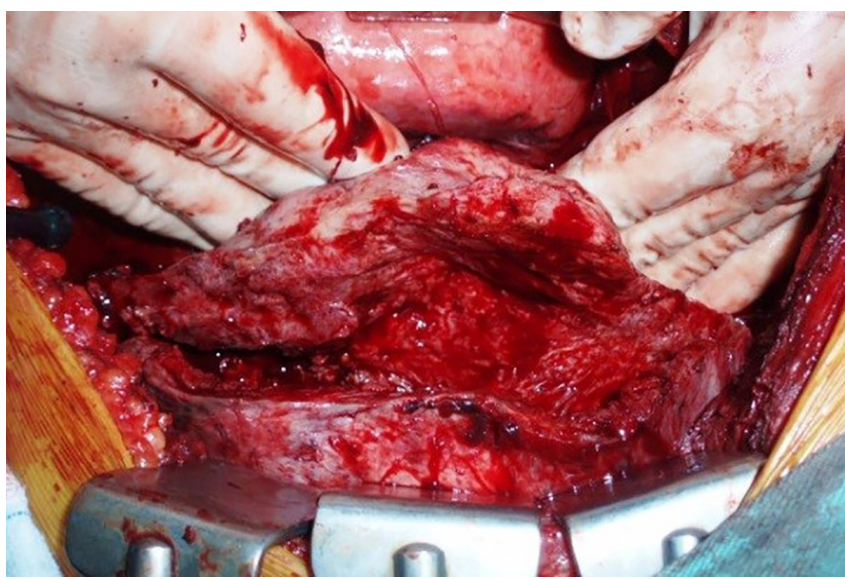

Figure 4. Progressive reduction of tumor mass.

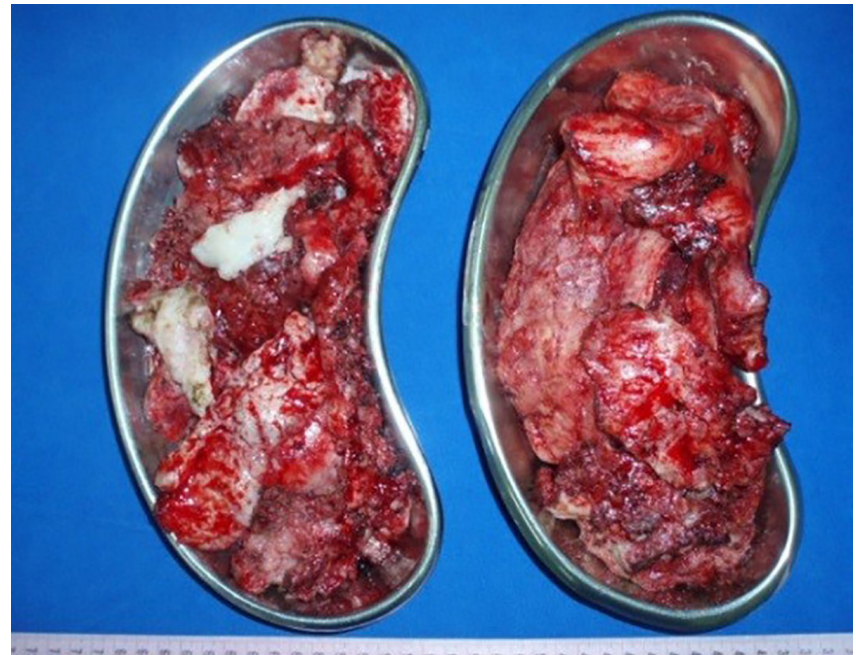

Figure 5. Tumor mass removed.

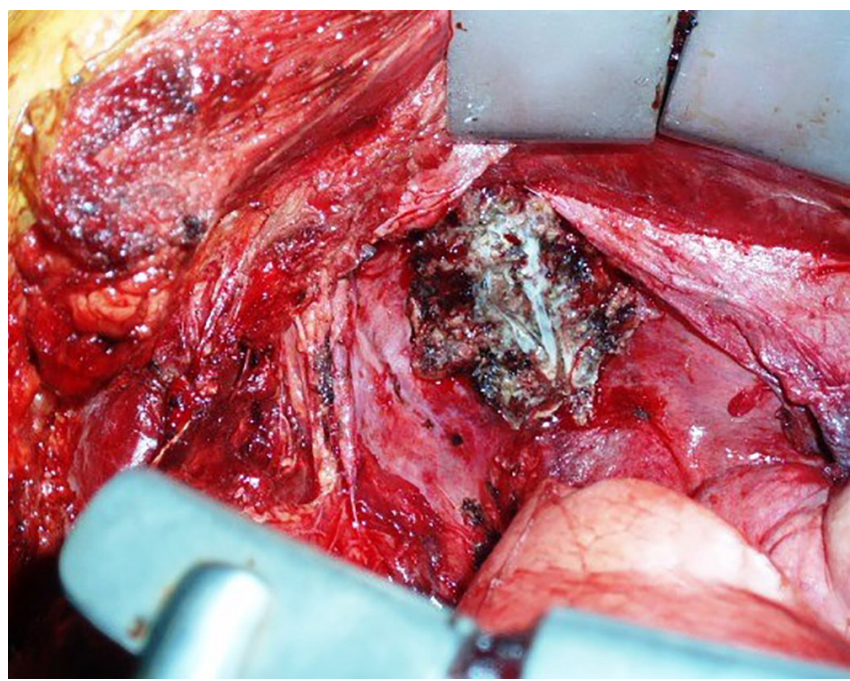

Figure 6. Malignant tumor invading brachial plexus.

\section{DISCUSSION}

The size of giant mediastinal tumors is a problem for surgical treatment, since it usually occupies a 
major part of thoracic cavity, preventing surgical maneuvers necessary for mobilization and tumor removal. Also, the involvement of surrounding major structures and tumor vascularization may justify the need of exceptional maneuvers, without which the patient would be considered inoperable ${ }^{4}$. Among proposed solutions, aspiration of tumor content, lowering its volume, cannot be used in solid tumors and is restricted to cystic tumors. Also, it was proposed embolization of vascular pedicles and the use of extracorporeal circulation, to reduce bleeding and ease tumor removal, but with unsatisfactory results ${ }^{4}$.

Video-thoracoscopic resection does not replace open approach of giant tumors, since the lack of enough space to move surgical instruments impairs vision, and although new and promising, this technique should only be used in the treatment of small lesions ${ }^{5}$.

Bilateral thoracotomy with transverse section of sternum ("clamshell operation") was also proposed. Although allowing for a broad vision of surgical field, it has some disadvantages such as increase of surgical trauma and consequent increase of complications incidence.
There is no consensus regarding clinical criteria to define a giant mediastinal tumor. It is considered giant when occupies more than half of one hemithorax. In spite of different locations, once the diagnosis is stablished, surgical treatment is mandatory ${ }^{6}$. This is a very difficult topic with tricky solutions, and it is justified the search for new techniques to help surgeons. The technique presented here ease removal of giant mediastinal solid tumors, and may be used with any incision, independent of the location. Once exposed, the lesion is resected with the aid of a routine instrument available for major thoracic surgeries.

We used the procedure in four patients (two with malignant tumors and two with benign tumors), with good early post-operatory evolution. Only one patient died at the 30th day of post-operatory, due to pulmonary embolism. The other patient with malignant tumor is still alive under oncologic treatment. Both patients with benign disease are alive and asymptomatic.

We conclude that tumor lamination technique is a valid alternative for resection of solid giant mediastinal tumors, allowing the removal of giant tumors without the need of exceptional maneuvers.

\section{RE S U M O}

Tumores do mediastino podem crescer lentamente e atingir proporções gigantes sem apresentar sintomas, tornando a remoção cirúrgica problemática. As dimensões exacerbadas da neoplasia dificultam as manobras cirúrgicas, com risco de hemorragia incontrolável e comprometimento de estruturas adjacentes, levando à utilização de medidas de exceção, como a derivação circulatória veno-venosa, a embolização pré-operatória e a circulação extracorpórea total. Diante disto, descrevemos a técnica de laminação tumoral, que permite a ressecção total ou quase total de tumores considerados, muitas vezes, irressecáveis, tendo por base os resultados alcançados em quatro pacientes portadores de neoplasias gigantes do mediastino.

Descritores: Cirurgia Torácica. Neoplasias do Mediastino. Procedimentos Cirúrgicos Operatórios.

\section{REFERENCES}

1. Mani VR, Ofkwu G, Safavi A. Surgical resection of a giant primary liposarcoma of the anterior mediastinum. J Surg Case Rep. 2015;2015(9). pii: rjv126.

2. Zaho H, Zhu D, Zhou Q. Complete resection of a giant mediastinal teratoma occupying the entire rigth hemithorax in a 14-year-old boy. BMC Surg. 2014;(14):56-8.

3. Makdisi G, Roden AC, Shen RK. Successful resection of giant mediastinal lipofibroadenoma of the thymus by video-assisted thoracoscopic surgery. Ann Thorac Surg. 2015;100(2):698-700.

4. Aydemir B, Çelik S, Okay T, Doğusoy I. Intrathoracic giant solitary fibrous tumor. Am J Case Rep. 2013;14:91-3.

5. Wang J, Yan J, Ren S, Guo Y, Gao Y, Zhou L. Giant neurogenic tumors of mediastinum: report of two cases and literature review. Chin J Cancer Res. 2013;25(2):259-62.

6. Yang C, Zhao D, Zhang P, Fei K, Jiang G. Intrathoracic neurogenic tumor with malignant transition-20 years 
operation experience in a medical center of China. Source of funding: none.

Neurosci Lett. 2017;(637):195-200.

Received in: 31/08/2017

Accepted for publication: 07/09/2017

Conflict of interest: none.

\section{Mailing address:}

Elias Kallas

E-mail: eliaskallas@uol.com.br/ clinicakallas@clinicakallas. com.br 